\title{
Economic Growth, Regional Savings and FDI in Sub-Saharan Africa: Trivariate Causality and Error Correction Modeling Approach
}

\author{
Rexford Abaidoo \\ Correspondence: Rexford Abaidoo, School of Business and Technology, University of Maryland Eastern Shore, \\ USA
}

Received: July 23, 2012 Accepted: August 17, $2012 \quad$ Online Published: September 25, 2012

doi:10.5539/ijef.v4n11p40 URL: http://dx.doi.org/10.5539/ijef.v4n11p40

\begin{abstract}
Empirical studies examining the dynamic causal relationship between key macroeconomic variables using varied forms of bivariate causality methodology abound in the macroeconomic and finance literature. Causal inference based on such bivariate causality approach however, has been criticized for its inherent likelihood to draw causal inference or attribute causation to variables in scenarios where an omitted variable might have a better claim; Lutkephol (1982), Umberto Triacca (1998). This study is modeled to reduce this inherent weakness by employing trivariate causality methodology through error correction approach. Using aggregate data on Sub-Sahara Africa spanning the period 1977 to 2010, this study finds joint uni-directional causal relationship running from FDI and Gross Regional Savings growth to regional GDP growth. Empirical results further document additional uni-directional joint causal relationship stemming from GDP growth and Gross Regional Savings to growth in FDI inflow into the sub-region.
\end{abstract}

Keywords: trivariate causality test, FDI, GDP growth, Error Correction Model, Sub-Saharan Africa

JEL Classification: O40, O55, C01, C87.

\section{Introduction}

The dynamic relationship between foreign direct investment (FDI) and economic growth among developing economies and regional economic blocks such as Sub-Saharan Africa (SSA), continue to receive significant empirical attention in the ever growing literature focusing on economic growth. A review of the literature show that most studies focusing on the FDI-GDP growth nexus, especially those centering on less developed economies, tend to concentrate on three main traditional benefits often attributed to FDI inflow. These traditional benefits centers on: 1) additional capital infusion into recipient economies, 2) the potential to generate auxiliary small scale domestic firms whose operations complements major firms and industries resulting directly from FDI, and, 3) the ultimate impact of FDI on domestic or regional economic growth. Empirical evidence (to be reviewed shortly) so far, overwhelmingly supports integral role of these FDI induced benefits on GDP growth in most economies in sub-Saharan Africa. The evidence show that, with limited regionally generated investment capital and technological knowhow, coupled with weak institutional structures to spur and self-sustain regional growth, economic blocks such as SSA have come to depend significantly on the volume of FDI inflow for economic growth. This reliance on FDI as the main catalyst for growth for most economies in the sub-region has been persistent over the years due to legion of socio-economic and geo-political factors; prominent among these being the region's deficit in growth augmenting technologies and access to capital. Recent regional growth data published by the United Nations Conference on Trade and Development (UNCTAD) for instance, show that the sub-region's dependence on external financial capital infusion and technological know-how continue to experience substantial growth despite inroads made in harnessing regional resources for growth. Key macroeconomic indicators further suggest that FDI inflow into the sub-region has gone through a transitional period; from an earlier phase of raw material extraction oriented form of FDI, to the present phase where the sub-region is now able to attract huge capital inflows into areas beyond the traditional phase which focused on raw material extraction. Available data show that significant portion of FDI inflows into the sub-region in recent years are channeled into production of finished goods for export and regional consumption, as well as investment in the services sectors of the various economies (e.g. banking services, wholesaling and retailing etc.). Regional macroeconomic data further show that significant percentage FDI inflow into the sub-region in recent years has come from emerging Asian economies such as China and India with former trading partners such as the United 
Kingdom playing a limited role. There is thus, enough data evidence in support of the view that appreciable growth conditions in the sub-region in recent years could be attributed in part, to increased volume of FDI inflow into the sub-region.

This growing interest in the sub-region from both developed and emerging economies around the world, coupled with designed policies aimed at attracting such external investments from most economies in the sub-region, has to a greater extent led to over-reliance on FDI as the press button for sustained growth SSA. GDP growth in the sub-region now depends heavily on the volume of FDI and FDI related activities. For instance, for most oil producing economies such as Nigeria, Ghana etc, GDP growth rates have come to depend extensively on FDI related operations in the energy (oil production) sector of the economy. Available data for instance show that proportion of FDI as a percentage of regional GDP growth for most economies in the sub-region continues to soar even as the sub-region as a whole struggles to find its place in the ever changing global market economy. Most private sector investments (considered as the engine for economic growth) found in the sub-region are dominated by auxiliaries of multinational firms or foreign private investments in partnership with local firms. Activities of these firms are mostly oriented to take advantage of the region's natural resources for export or to supply parent companies in developed economies. The case of Cadbury Company Limited, UK, and its investments in cocoa producing economies in the sub-region are examples of this form of FDI orientation. Growing importance of FDI to regional economic growth is also readily evident from the legion of regional macroeconomic economic policies geared towards attracting such investments into the region; most economies in the sub-region for instance, are involve in vigorous campaign aimed promoting extensive incentive laden FDI oriented policies designed to attract additional investments to complement domestic productivity. Programs such as free already developed industrial zones, tax holidays for specified operational period, accommodating profit repatriation laws etc. are some of the policy initiatives specifically designed to attract FDI into the sub-region.

Although existing literature provide verified evidence in support of the positive role of FDI in economic growth among developing economies and regional economic blocks such as SSA, critical review of the literature further suggests the extraordinary role often attributed to FDI in the economic growth process might be overstated. This study also hinges on the view that the role of FDI in domestic or regional growth may be limited compared to what most bivariate causality analysis tend to suggest. This study further projects that effects of FDI on economic growth may not be automatic as often portrayed existing empirical work, in that, such effects are often contingent on other socio-economic and geo-political factors. For instance, strands of dissenting literature exist to the effect that FDI alone cannot be the panacea for constrained growth in in most developing economies such as those in SSA. Empirical evidence (to be reviewed in subsequent sections) further suggest that FDI inflow is only a necessary condition for regional growth; since it's impacts on economic growth depend significantly on other core growth augmenting regional socio-economic factors. Regional benefits such as substantial infrastructure development, infusion of hitherto unavailable technologies and capital, and potential employment growth for host economies associated with FDI are not in dispute; however, this study is among limited studies in the evolving FDI-Economic Growth literature questioning the singular role often accorded to FDI in the economic growth process espercially among developing economies.

This study undoubtedly subscribe to empirically verified condition that FDI inflow is crucial for GDP growth in SSA; however, it is also of the view that FDI inflow fundamentally functions as an auxiliary condition in the economic growth process and not the core or the principal variable around which regional growth revolve. This position stems from projected condition suggesting that, given the proportion of domestic or regional investments needed to significantly impact economic growth, FDI inflow alone, devoid of thriving auxiliary regional or domestic private sector investments, might not be enough to generate required impetus for significant economic growth. Thus, FDI inflow into SSA alone might not be enough to fuel expected economic growth in the Sub-region. Consequently, FDI inflow in this study is viewed as a marginal investment flow which requires some form of regional or domestic support to significantly impact regional economic growth. What constitutes critical regional supporting factors however, differ significantly among researchers. Zhang (2001) for instance, argued in favor of institutional quality, political stability, and significant infrastructure development base. Zhang's work further showed that FDI inflow tend to promotes economic growth in economies where domestic infrastructures are well developed and trade and FDI policies are more liberal. This study however, subscribe to the view that regional savings conditions - [regionally generated financial resource crucial for creating auxiliary financial base for regional investors]- constitute a key regional factor needed to augment FDI inflow to ensure sustained investment-led regional economic growth. Gross regional savings is deemed as the needed regional supporting factor in this study because of its unique potential to foster domestic private sector investments crucial for long term economic growth. 
Available literature (Note 1) on the nexus between FDI and GDP Growth show that significant number of present studies employed bivariate causality estimation approach in their effort to unravel potential dynamic causal relationship between the variables. Dominant among these bivariate causality methodologies found in the literature include bivariate Granger Causality tests formally propounded by Granger (1969), and a projected robust variant of the approach by Toda Yamamoto, Toda, H.Y. and Yamamoto T. (1995). These approaches to causal inference estimation have become prevalent among researchers partly because of their intuitive nature and simplicity. Growing popularity of these bivariate causality methodologies further highlights evolving trends in empirical methodology geared towards isolation of critical variables in a quest to ascertain potential causal relationships among core variables of interest. Unlike bivariate causality methods which dominate the literature, this study opts for trivariate causality error correction approach (multivariate approach) to verify joint causal relationships among key macroeconomic variables of interest from SSA. Trivariate causality approach adopted in this study test causal effect of two key macroeconomic variables on a specific macroeconomic variable of interest from SSA instead of causal effect of just one variable as done in a bivariate framework. The goal is to verify the presence long run joint causal relationships among key macroeconomic variables of interest for SSA via trivariate causality methodology. This approach will afford this study the opportunity to identify direction of causal relationships due to joint effects of two key variables from the sub-region instead of single variable approach which dominates the literature.

The rest of the study is structured as follows: section 2 reviews data on FDI, GDP growth and Savings growth trends in SSA. This is followed by a review of the literature focusing on the dynamic relationships between combinations of key variables employed in this study in section 3. FDI-GDP growth nexus is first review, followed by verified causal relationship between GDP growth and savings rates in that order. This section then concludes with empirical review of the relationship between FDI and growth rate in savings conditions. Sources of data and empirical methodology used in this study's empirical estimations are reviewed in section 4. Section 5 report empirical results and findings as well as conclusion and possible policy implications of verified causal relationships.

\section{FDI, GDP Growth and Regional Savings Trends}

\subsection{FDI as a Percentage of GDP in SSA}

FDI growth in SSA continues to be a key macroeconomic trend influencing socio-economic conditions in the sub-region. GDP growth conditions associated with a number of economies in the sub-region, and the region as a whole, have over the years come to revolve to some degree, around the rate and volume of FDI inflows. Available data (UNCTAD DATA) show that the rate of FDI flow into the sub-region differ markedly among individual economies due to country specific factors such as differences in resource endowment which influence the form and volume of FDI inflow and prevailing socio-political environment. This notwithstanding, the data shows aggregate growth in FDI attracted into the region as a whole has experience significant growth in the past two decades. Like most macroeconomic indicators in the region, FDI growth over the years has been fraught with periods of significant fluctuations. Figure 1 illustrates FDI growth as a percentage of GDP growth conditions for SSA; with significant positive growth trend variability. Figure 1 indicates between 1980 and later part of the 1990s, FDI as a percentage of GDP growth experienced relatively minimal but sustained growth. The early part of the year 2000 however witnessed substantial growth in FDI for the sub-region, with FDI as a percentage of GDP growth peaking around $4.5 \%$. This sharp growth in FDI over the period however, was short-lived; the trend then declined substantially afterwards and fluctuated until another episode of growth burst was recorded between 2006 and later part of 2008. This mild growth condition persisted until the trend succumbed to the effects of the 2008 global recession evidenced by marked decline in 2009. Figure 1 illustrates FDI growth for SSA between 1977 and 2010. 


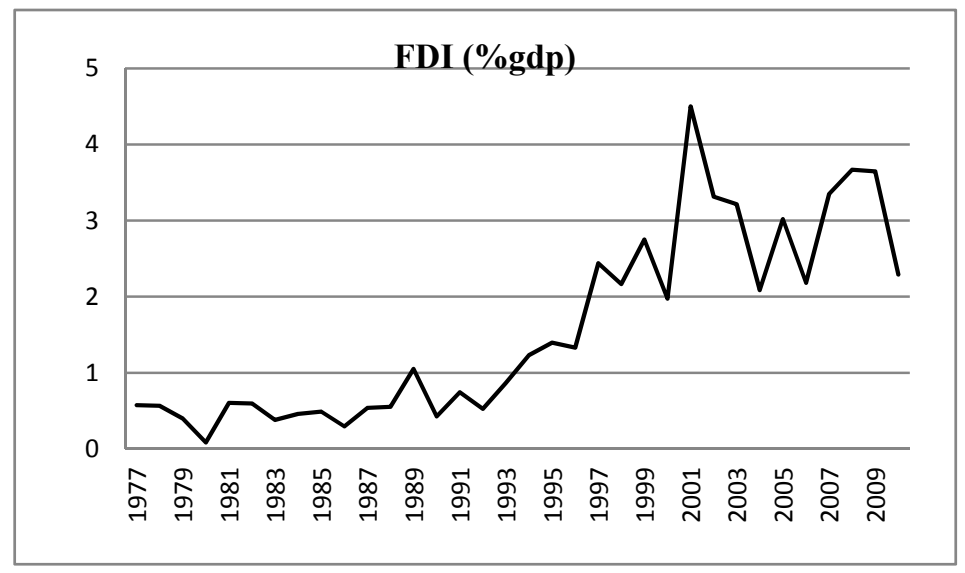

Figure 1. FDI as a percentage of GDP in SSA

Data Source: UNCTAD

\subsection{Structure of GDP in SSA}

GDP growth in the sub-region exhibits extreme trend variability over the period under study. Periods of significant growth are short-lived, often interrupted by substantial declining trend. Figure 2 show that between 1977 to date, the SSA region has experienced two major episodes of substantial decline in GDP growth in addition to the recent decline following the 2008 recession. The first major decline in GDP growth over the period occurred in the early part of the $1980 \mathrm{~s}$, and the second in the early part of the 1990s. According to available data, these two periods recorded the only conditions of negative GDP growth over the period under study for the sub-region. Apart from mostly socio-economic and political conditions which often constrain GDP growth conditions in the sub-region according to available literature, there is also some evidence that GDP growth trend in the sub-region has also been shaped to some degree by global macroeconomic conditions. For instance, the data show that sharp decline in GDP growth recorded in the later part of 2008 and early 2009 were in responds to the 2008 global financial crisis. Figure 2 charts annual regional GDP growth conditions in SSA over the study period.

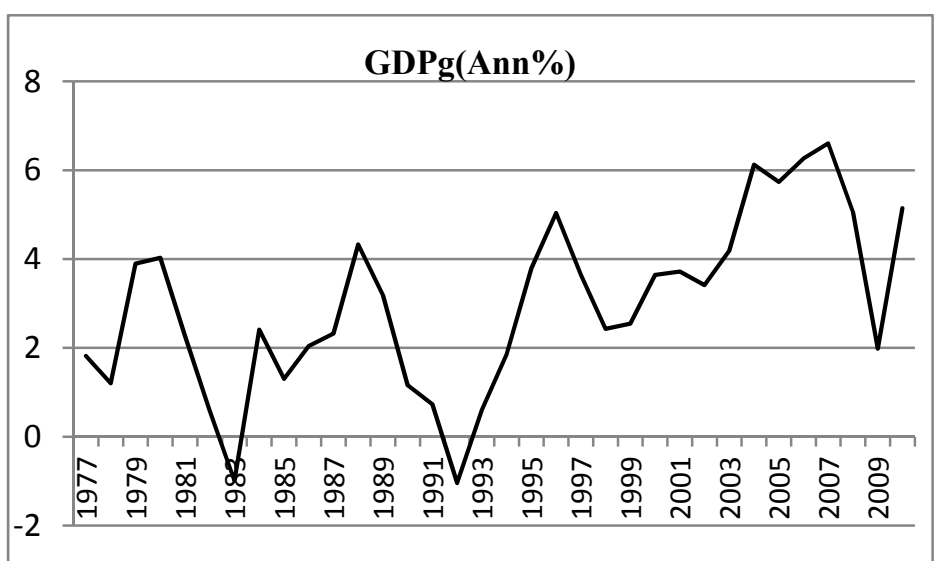

Figure 2. Annual GDP growth in SSA

Data Source: UNCTAD

\subsection{Gross National Savings as a Percentage of GDP Growth in SSA}

Among macroeconomic variables employed in this study, gross regional savings as a percentage of GDP growth is the only variable with fairly sustained negatively sloped growth trend. This condition suggest that, over the period under study, gross national savings as a percentage of GDP for SSA witnessed persistent decline despite fairly sustained growth in FDI and appreciable GDP growth among most economies in the sub-region. From a peak of about $24 \%$ of GDP growth in the late 1970 s, regional savings have declined persistently; and now hovers 
around $16 \%$ of GDP growth on the average. Although this decline in gross regional savings over the period is not as drastic as variability associated with other key indicators such as regional GDP growth, it suggest a diverging trend between FDI growth and savings rate in the sub-region over the past decades. Figure 3 captures historical trend in regional gross savings as a percentage of GDP growth between 1977 and 2010.

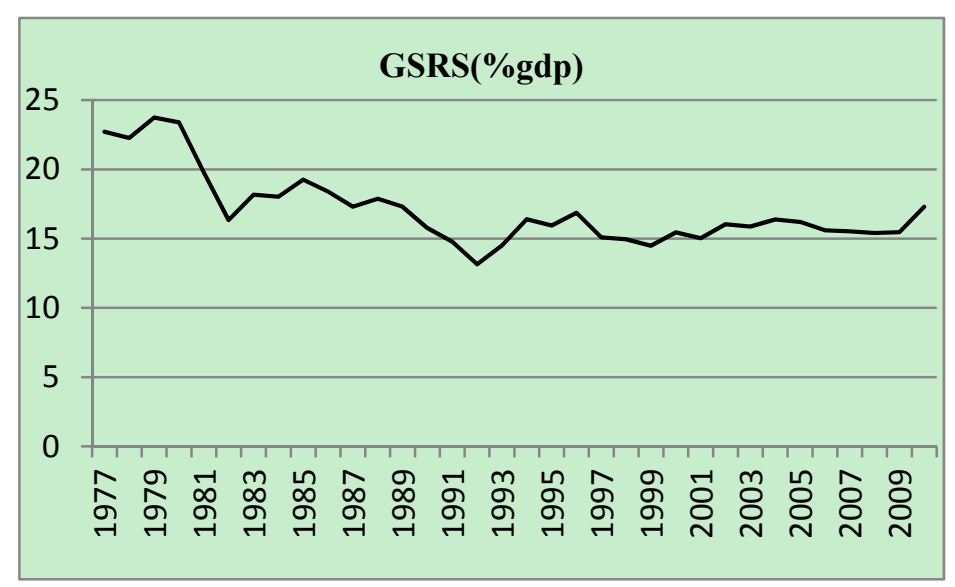

Figure 3. Gross National Savings as a percentage of GDP growth in SSA

Data Source: UNCTAD

\section{Empirical Literature: FDI, GDP Growth and Domestic Savings Rate}

\subsection{FDI and GDP Growth}

Empirical literature focusing on the FDI-GDP growth nexus is quite extensive; and captures conditions prevailing in both developing and developed economies around the world. Reviewed evidence suggests evolving trends in globalization, and the effects of the phenomenon on recent FDI flows continue to drive the quest to understand the dynamic relationship between key macroeconomic variables and FDI flows around the world. Using co-integration and an error-correction framework, Chakraborty and Basu (2002) for instance, examined the relationship between FDI and economic growth in India; contrary to most empirical findings in existing literature, this study found uni-directional causal relationship with direction of causality running from GDP growth to FDI growth with no feedback effect. Hsiao and Shen (2003) further documented bi-directional causal relationship between FDI and growth in China; an indication of feedback effect relationship between FDI and GDP. Additionally, in a study focusing on 23 developing economies around the world, Basu, Chakraborty and Reagle (2003) also found bi-directional causal relationship between FDI and GDP growth in more open economies, and a uni-directional causal relationship running from GDP growth to FDI in more closed economies. Trevino and Upadhyaya (2003) further documented comparable results in a study of five developing economies in Asia; the study showed that FDI tend to have significant positive influence on economic growth in more open economies - further supporting causal relationship stemming from FDI to GDP growth among open economies. Additionally, in a study verifying the dynamic relationship between FDI and economic growth in Indonesia, Thailand, Philippines and Malaysia, Marwah and Tavakoli (2004) also found evidence in support of positive correlation between FDI and economic growth for all the economies studied.

Li and Liu (2005) who studied endogenous relationship between FDI and economic growth using a panel of 84 countries over the period 1970-1999; additionally concluded that FDI has positive impact on economic growth. $\mathrm{Li}$ and Liu (2005) further pointed out that this verified positive relationship is significantly moderated by human capital availability in the various developing economies studied. In the same study however, the researchers also found negative relationship between FDI and economic growth in the presence of significant technology gap. Choe (2003) adopted panel vector auto regressive model to evaluate the relationship between FDI and economic growth in eight countries over the period 1971 and 1995; Choe's work also documented evidence of bi-directional causal relationship between FDI and economic growth; with relatively stronger causal effects emanating from economic growth to FDI rather than the reverse condition. Alfaro et al (2002) additionally argued that effect of FDI on economic growth depends to some extent, on the degree of domestic financial sector development; and submitted that economies with well-developed financial markets tend to gain significantly 
from FDI inflows than those with underdeveloped financial markets. In a special case focusing on the same nexus among Latin American economies, Bengoa et al. (2003) also verified this nature of relationship using a panel of eighteen Latin American countries. This study again overwhelmingly supported prevailing empirical evidence suggesting that FDI has significant positive impact on economic growth; this positive relationship was verified among all economies in the study.

However, these conclusive empirical findings notwithstanding, there also exist significant strands of existing literature suggesting that FDI inflow alone has minor, weak or no significant effect on economic growth. Segments of existing literature further contend that FDI's impact on economic growth is conditional or depends on other auxiliary domestic/regional factors or enabling conditions. For instance, Campos and Kinoshita (2002) showed that FDI inflows will have positive and significant effect on economic growth only if it is in the form of pure technology transfer which has the potential to impact other key sectors of the economy. Similarly, utilizing General Method of Moment approach in a similar FDI-economic growth nexus study, Carkovic and Levine (2005) submitted that FDI inflows do not exert influence on economic growth directly, nor through its effect on human capital as has been suggested in some studies; this conclusion was based on the fact that, most studies reporting positive causal relationship between FDI and economic growth often fails to control for simultaneity bias and country-specific effects in their analysis. Additionally, studies such as Akinlo (2004) and Aynwale (2007) have found FDI to have insignificant effect on economic growth all things being equal. Hermes and Lensink (2003) and Sylwester (2005) even suggest that FDI tend to have negative effects on host economies under certain conditions.

\subsection{GDP Growth and Domestic/Regional Savings}

Empirical submissions on the causal relationship between GDP growth and regional or domestic Savings rate differ significantly among researchers; however, the view that some form of causal relationship exists between the two variables is largely supported by the literature. A review of existing studies however show that most findings reported are in conflict with projections of the Solow growth framework; a well referenced growth economic model which suggest that domestic savings rate temporary causes growth in the level of output per capita; a condition which imply savings rate growth precedes economic growth all things being equal. For instance, Christopher et al. (1994) who examined the association between saving rate and economic growth using a sample of 64 economies concluded that economic growth autoregressively predicts future saving rates, without feedback effects. In other words, this study found conclusive evidence in support of the condition that economic growth precedes domestic savings rates contrary to reverse condition suggested by the Solow growth framework. Again, focusing on the savings rate-economic growth nexus in Latin America, Gavin et al. (1997), further showed that sustained economic growth precedes higher savings rather than the reverse condition; another conclusion suggesting causality running from economic growth to savings rate with no feedback effect. Similarly, Sinha and Sinha (1998), and Agarwal (2001) also confirmed that economic growth precedes and Granger cause higher savings rate all things being equal. In an estimation focusing on a similar causal relationship in the case of Nigeria, Nurudeen Abu (2010) also submitted that economic growth Granger cause savings growth in the Nigerian economy; further supporting evolving view that economic growth precedes or Granger cause growth in domestic savings.

In a related study examining the long-run relationship between real gross domestic product and real gross domestic savings in Morocco and Tunisia, Bassam AbuAl-Foul (2010), found bi-directional causal relationships between the variables in the case of Morocco. The study however, found uni-directional Granger causality between real gross domestic product and real gross domestic savings for the Tunisian economy- with direction of causality running from savings rate to economic growth. Sajid and Sarfraz (2008) who investigated causal relationship between savings and output growth in Pakistan using co-integration and vector error correction techniques further supported significant bi-directional long run causal relationship between domestic savings and output growth. In another study which focused on verifying similar relationship among seven African economies, Anoruo and Ahmad (2001) also submitted that economic growth Granger cause growth rate in domestic savings for all the countries treated in the study with the exception of Congo. Narayan and Narayan (2006), additionally provided evidence in support of the fact that that GDP growth stimulates savings growth in Fijian economy thus further supporting uni-directional causal relationship all things being equal. These empirical findings suggest that the exact direction of causal relationship between these two macroeconomic indicators deviates somehow from earlier projections.

\subsection{FDI and Domestic Savings}

FDI inflows have also been credited with significant positive impact on regional/domestic savings among 
developing and emerging economies. This study projects that the dynamic relationship between FDI and domestic savings will depend on how FDI impacts regional GDP growth. In other words, effect of FDI on savings rate is projected to be channeled through GDP growth all things being equal. This projection presumes that any verified causal relationship between the two variables might stem from FDI inflows to domestic savings and not the reverse condition. Bashier and Bataineh (2007) investigated this dynamic relationship, FDI-savings nexus, and showed that the variables are co-integrated or has a long run relationship; the study further submitted that FDI significantly complement national savings; suggesting some form of positive causal relationship stemming from FDI to national savings. In another study focusing on a similar relationship in the case of Pakistan, Shahbaz et al. (2008) also showed that foreign direct investment and domestic savings are complementary; augmenting each other in a dynamic relationship pertaining to growth. Additionally, in a relatively recent study, Salahuddin, Shahbaz, Irfan Chani (2010) also confirmed bi-directional causal relationship between foreign direct investment and gross domestic savings in Bangladesh using Johansen cointegration and error correction techniques; the study further showed that, causal influence between the variables tend to be stronger from domestic savings to foreign direct investment than the reverse condition.

\subsection{Data and Test Variables}

This study employs aggregate data for SSA between the period 1977 and 2010. Key data variables used in this study are GDP growth, FDI growth and Gross Regional Savings rate. Gross regional savings is chosen over regional investment growth in a trivariate framework due to difficulty in isolating absolute regional investments from component strictly due to FDI inflow from available data. These data points have been sourced from the International Monetary Fund (IMF) data base and United Nations Conference on Trade and Development data base (UNCTAD) respectively.

\section{Empirical Methodology}

\subsection{Empirical Model and Stationarity Test}

This study recognizes that in a dynamic macroeconomic economic environment, a number of factors are often responsible in explaining observed variability in a macroeconomic variable or indicator. However, trivariate causality test approach adopted in this study presumes that variability in a specific macroeconomic variable of interest could be explained to some degree by happenings of two critical (related/unrelated) variables instead of one key variable of interest often used in bivariate causality analysis; consequently three equations modeling trivariate causal relationship approach are stated after pre-estimation data analysis. Stationary conditions of individual time series variables in this study are tested using unit root testing methodology proposed by Phillips P.C.B and P. Perron (1988). Equation 1 models unit roots test approach and table 1 report results from pperron estimation procedure using Stata Statistical software package. Initial unit root test using specific lag order and related first difference results are reported. Results reported in table 1 show that, using specific lag order determined by Akaike Information Criterion (AIC) and Bayes-Schwartz Information Criterion (BSIC) procedures, the null hypothesis of unit root cannot be rejected for the three variables tested; the first difference of the three variables however, are stationary. Unit root tests for individual variables are modeled as follows:

$$
\Delta y_{\mathrm{t}}=\beta^{\prime} J_{\mathrm{t}}+\pi y_{\mathrm{t}-1}+u_{\mathrm{t}}
$$

Where $u_{\mathrm{t}}$ is $I(0)$ and may be heteroskedastic. Philips Perron tests modeled in equation 1 corrects for serial correlation and heteroskedasticity in the errors $\left(u_{\mathrm{t}}\right)$ of regressions by directly modifying associated test statistics. Table 1 reports results of Philips-Perron Unit root test for study variables.

Table 1. Unit Root Test: Phillips-Perron Test for Unit Roots

\begin{tabular}{lccclcc}
\hline Variables & Pperron-Stats & Lag & Results & First Difference & Pperron-Stats & Results \\
\hline FDI(\%GDP) & -4.678 & 2 & $\mathrm{I}(1)$ & $\Delta$ FDI $(\% \mathrm{GDP})$ & -49.083 & $1(0)$ \\
GDP & -11.382 & 2 & $\mathrm{I}(1)$ & $\Delta \mathrm{GDP}$ & -32.121 & $1(0)$ \\
GRS(\%GDP) & -6.360 & 2 & $\mathrm{I}(1)$ & $\Delta \mathrm{GRS}(\% \mathrm{GDP})$ & -28.378 & $1(0)$ \\
\hline
\end{tabular}

Significant at $1 \%$ Critical Values.

Pperron statistics reported in table 1 are based on a lag order of 2 selected by AIC and BSIC respectively; first part of the result indicates the three variables are not stationary. First difference of the variables however, was found to be stationary. Non-stationary condition found in the first test show the variables satisfy the first 
condition in a test for long run relationship using co-integration procedure. Co-integration methodology in this context tests the assumption that, although variables in the study exhibit non-stationary individual trends, such trends might not be a 'random walk'; in that, a combination of the variables may have long run relationships. In this co-integration estimation using error correction framework, (approach adopted in this study) if time series data for the three variables are found to share equilibrium relationship with an error correction mechanism, then the stochastic trends of the time series data will correlate with one another- thus, implying co-integration or long run relationship.

\subsection{Trivariate Causality Test - An Error Correction Approach}

As alluded to earlier, significant number of empirical studies verifying the nexus between combinations of any the three variables employed in this study (as evidenced in the literature review) is based on bivariate causality framework. Although this framework continue to be an effective tool in verifying causal relationships between key variables of interest, empirical evidence also suggest that the approach has inherent flaw in how it identifies the source or direction of causal influence between variables. For instance, the approach has been criticized for its narrow focus on only a source or variable as the causal agent of an occurrence or changes in another variable. Critics suggest that in an environment devoid of potential causal agents or variables, bivariate framework might erroneously attribute causation to the only known agent or variable in treatment. Granger (1969) and Lutkephol (1982) for instance, suggested a highly plausible scenario where an omitted variable could be responsible for a verified causal relationship between two variables of interest in a bivariate framework. In other words, their work allowed for the chance that an omitted variable or one outside the test environment could be responsible for verified causal relationship between two treatment variables. Umberto Triacca (1998) additionally offered empirical evidence on how omitted variables could have a better claim in a higher-order system causality analysis than a purported causal agent or variable in treatment. Critics of bivariate causality approach further point out that if omitted variables in a treatment correlates with variables included in a test, bivariate approach may attribute causation to a variable included in a treatment or test when in fact an omitted variable which correlates with the variable in treatment may be responsible or have a better claim as the causal agent. For instance, if variable $\delta$ is known to correlates with variable $\mu$, and it could further be shown that variable $\mu$ granger cause changes in variable $\Omega$ in a hypothesized bivariate causality framework; critics then argue that, the omitted variable in this scenario, $\delta$ could have a better claim as the causal agent instead of variable $\mu$. This position is based on the view that bivariate approach in this example might have erroneously attributed causality to variable $\mu$ because of its association with variable $\delta$ or just because variable $\delta$ happen to be omitted from the test. To minimize this possibility, this study estimates joint influence of two macroeconomic variables on a macroeconomic variable of interest in a trivariate causality framework. Trivariate or multivariate causal analysis has been suggested as a means to reduce the chance of erroneously attributing causality to test variables in cases when other variables could have a better claim. Lutkephol (1982) for instance, suggested that multivariate system having more than two variables may be more useful in causality analysis than a bivariate framework. Trivariate causality model using error correction approach is consequently modeled as follows:

$$
\begin{aligned}
& \Delta G D P g_{t}=\mathrm{c}_{l}+\sum^{p-t} \beta_{t} \Delta G D P g_{t-i}+\sum^{p-l} \gamma_{\mathrm{t}} \Delta F D I g_{t-i}+\sum^{p-l} \psi_{t} \Delta G R S g_{t-i}+\omega E C_{t-i}+u_{1} \\
& \Delta F D I g_{t}=\mathrm{k}_{l}+\sum_{j=1}^{p-l} \delta_{t} \Delta F D I g v_{t-i}+\sum_{j-l}^{j=l} \lambda_{\mathrm{t}} \Delta G D P g_{t-i}+\sum_{j=1}^{p-l} \eta_{t} \Delta G R S g_{t-i}+\omega E C_{t-i}+e_{1} \\
& j=1 \quad j=1 \quad j=1 \\
& \Delta G R S g_{t}=\mathrm{j}_{l}+\sum_{j=1}^{p-\imath} \alpha_{t} \Delta G R S g_{t-i}+\sum_{j=I}^{p-\imath} \rho_{\mathrm{t}} \Delta G D P g_{t-i}+\sum_{j=1}^{p-\iota} \sigma_{t} \Delta F D \operatorname{Ig}_{t-i}+\omega E C_{t-i}+\varepsilon_{1}
\end{aligned}
$$

In equations 1, 2, and 3, GDPg, FDIg and GRSg represent GDP growth, FDI growth and Gross Regional Saving rate in Sub-Saharan Africa respectively. $E C$ is the error correction term and $u_{1}, e_{1}$ and $\varepsilon_{1}$ are errors terms for individual equations. Equation 1, 2 and 3 models joint causal effects of two macroeconomic variables on specific variable of interest in a trivariate causality framework. Equation 1 for instance, hypothesize that gross regional savings and FDI growth jointly granger cause GDP growth in SSA if: $\mathrm{H}_{0}: \gamma \mathrm{t}=\psi \mathrm{t}=0$ is rejected. Equations 2 and 3 follow similar procedures and are modeled in the following section.

To test associated hypothesis of trivariate causal relationships based on equations 1, 2 and 3, let $\boldsymbol{Y}$ represent GDPg, $\boldsymbol{F}$ for FDIg and $\boldsymbol{S}$ for GRSg respectively. Using these notations this study tests the following trivariate causal relationships: 
(a) $\boldsymbol{F}$ and $\boldsymbol{S}$ jointly Granger cause $\boldsymbol{Y}$ if the null hypothesis of $\gamma_{\mathrm{t}}=\psi_{t}=0$ is rejected.

(b) $\boldsymbol{Y}$ and $\boldsymbol{S}$ jointly Granger cause $\boldsymbol{F}$ if the null hypothesis of $\lambda_{\mathrm{t}}=\eta_{t}=0$ is rejected.

(c) $\boldsymbol{Y}$ and $\boldsymbol{F}$ jointly Granger cause $\boldsymbol{S}$ if the null hypothesis of $\rho_{\mathrm{t}}=\sigma_{t}=0$ is rejected

(d) Feedback effects exist if hypothesis (a), (b), and (c) are shown to hold simultaneously

\section{Empirical Results}

Table 2 .Trivariate Causality Results (Error Correction Approach)

\begin{tabular}{|c|c|c|c|}
\hline \multicolumn{2}{|c|}{ Independent } & \multicolumn{2}{|c|}{ Dependent Variables } \\
\hline \multicolumn{4}{|c|}{ Variables } \\
\hline & $G D P g$ & FDIg & $G R S g$ \\
\hline \multirow[t]{2}{*}{$G D P g$} & - & 0.2575 & -0.4868 \\
\hline & - & $(0.080)^{* *}$ & $(0.156)^{* *}$ \\
\hline \multirow[t]{2}{*}{ FDIg } & 0.6047 & - & 0.3890 \\
\hline & $(0.222)^{*}$ & & $(0.375)$ \\
\hline \multirow[t]{2}{*}{ GRSg } & 0.5272 & -1.2182 & - \\
\hline & $(0.195)^{*}$ & $(0.705)^{*}$ & - \\
\hline$E C_{t}$ & $-0.8460 *$ & $-0.4543 *$ & 0.7404 \\
\hline
\end{tabular}

Standard errors in parenthesis, *Denote level of significant

Reported results in table 2 indicate two out of three error correction terms $\left(E C_{\mathrm{t}}\right)$ are significant. The first error correction term which test for co-integrating equation with gross domestic product (GDPg) as the dependent variable is significant; a condition which suggest existence of long run joint causal relationship emanating from foreign direct investment and gross regional savings to economic growth in SSA. The condition further highlights short run causal relationships between FDIg and GDPg, and GRSg and GDPg respectively; with causal influence stemming from FDIg and GRSg respectively. Additionally, the coefficient of error correction term with foreign direct investments (FDIg) as the dependent variable is also statistically significant, further suggesting existence of joint long run causal relationship running from economic growth and gross regional savings to foreign direct investments. This outcome also implies another short-run uni-directional causal relationship between GDPg and FDIg, and GRSg and FDIg, with the direction of causality running from $G D P g$ and GRSg respectively. The error correction term estimating trivariate joint causal relationship with GRSg as the dependent variable is however found to be insignificant; an outcome which suggesting failure to verify this specific joint causal relationship. Table 3 further present results of hypothesis tests verifying similar joint causal relationships among the three macroeconomic indicators in this study; this hypothesis tests are meant to further verify conclusions already reported in table 2 .

Table 3. Hypothesis Testing for Joint Causal Relationships

\begin{tabular}{lcc}
\hline Null Hypothesis $\left(\mathrm{H}_{0}\right)$ & Test Stat $(\mathrm{F})$ & Causal Inference \\
\hline $\begin{array}{l}\text { FDIg and GRSg do not jointly Granger cause } \\
\text { variability in GDPg }\end{array}$ & $4.79^{* *}$ & Reject $\mathrm{H}_{0}$ \\
\hline $\begin{array}{l}\text { GDPg and GRSg do not jointly Granger cause } \\
\text { variability in FDIg }\end{array}$ & $7.22^{* *}$ & Reject $\mathrm{H}_{0}$ \\
\hline $\begin{array}{l}\text { GDPg } \text { AND FDIg do not jointly Granger cause } \\
\text { variability in } \text { GRS }\end{array}$ & 0.43 & Failed to Reject \\
\hline
\end{tabular}

$* *$ significant at $5 \%$ level

Table 3 report results of trivariate causality hypothesis test. Test results in this instance are consistent with test results reported in table 2. For instance, table 3 also show that the null hypothesis of no joint causal relationship stemming from $F D I g$ and $G R S g$ to $G D P g$ is rejected; implying significant joint causal relationship running from FDIg and GRSg to GDPg. Similar outcome is further found in the case of joint causal relationship stemming from GDPg and GRSg to FDIg; further supporting the second case reported in table 2. This result also shows significant rejection of the null hypothesis of no joint causal relationship emanating from GDPg and $G R S g$ to 
FDIg. Reported test results in table 3 however, failed to find significant evidence in support of a joint causal relationship stemming from $G D P g$ and $F D I g$ to $G R S g$; another condition consistent with findings reported in table 2. Test results in this case failed to reject the null hypothesis of no joint causal relationship. These results provide significant empirical evidence in support of augmenting role played by regional savings in FDI-led growth in SSA. Altogether, these findings support initial projections that effects of FDI inflow on economic growth in SSA is significantly influenced by or depend on other key macroeconomic variables or conditions.

\section{Concluding Remarks and Policy Implications}

This study verified joint causal relationships between selected macroeconomic variables and specific macroeconomic indicators for SSA using a trivariate causality error correction approach. Empirical findings suggest that FDI and gross regional savings in SSA, jointly Granger cause GDP growth all things being equal. In other words, FDI and gross regional savings jointly explains to some degree, GDP growth dynamics in the sub-region. This outcome supports the view that there is a regional/domestic dimension to the extent to which FDI inflow impacts regional economic growth. The outcome further suggest that, policies geared towards promoting sustainable regional economic growth should not be oriented solely towards attracting FDI as most economies in the sub-region are known for; such policies should also incorporate a means of mobilizing regional savings to support local investments to augment economic boost generated by FDI inflow. This study further finds that all things being equal, economic growth and regional savings rate jointly Granger cause FDI growth in SSA. This result further suggests that foreign direct investments into SSA to some extent depend on regional economic growth dynamics and savings conditions. This finding shows regional/domestic macroeconomic conditions play significant role in attracting foreign direct investments into the sub-region. These results ultimately call for recalibration of existing regional macroeconomic policies which are often structured purposely and solely to attract FDI with little emphasis on improving regional/domestic macroeconomic conditions. Such restructured policies which take into consideration the role of regional macroeconomic performance will help the sub-region nurture long term growth defined by regional performance indicators with FDI inflow serving as auxiliary condition.

\section{References}

Abu Nurudean (2010). Saving-Economic Growth Nexus In Nigeria, 1970-2007: Granger Causality And Co-Integration Analyses. Review of Economics and Business Studies, 3(1), 93-104.

Agarwal, P. (2001). The Relation between Saving and Growth: Co-integration and Causality Evidence from Asia. Applied Economics, 33, 499-513. http://dx.doi.org/10.1080/00036840122210

Akinolo, A. (2004). Foreign Direct Investment and Growth in Nigeria: An Empirical Investigation. Jourrnal of Policy Modeling, 26, 627-639. http://dx.doi.org/10.1016/j.jpolmod.2004.04.011

Al-Abdulrazag, B., \& Bataineh, T. M. (2007). Causal Relationship between Foreign Direct Investment and Savings in Jordan: An Error Correction Model. International Management Review, 3(4), 12-18.

Alfaro, L, A. Chanda, S. Kalemli-Ozcan, \& S. Sayek. (2002). FDI and Economic Growth: The Role of Local Financial Markets. Working Paper No. 01-083, Harvard Business School, http://ssrn.com/abstract=305762.

Anoruo, E., \& Y. Ahmad. (2001). Causal Relationship between Domestic Savings and Economic Growth: Evidence from Seven African Countries. African Development Bank, Blackwell publisher, Oxford.

Ayanwale, A. B. (2007). FDI and Economic Growth: Evidence from Nigeria. Nairobi. (African Economic Research Consortium Paper No. 165).

Bassam, AbuAl-Foul. (2010). The Causal Relation between Savings and Economic Growth: Some Evidence from MENA Countries, Being a Paper Presented at the 30th MEEA Meeting in Atlanta, January.

Bengoa, M., \& Sanchez-Robles. (2003). FDI, Economic Freedom, and Growth: New Evidence from Latin

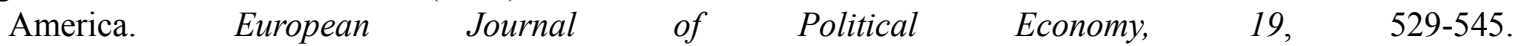
http://dx.doi.org/10.1016/S0176-2680(03)00011-9

Campos, N., \& Y. Kinoshita. (2002). Foreign Direct Investment as Technology Transferred: Some Panel Evidence from the Transition Economies. The Manchester School, 70, 398-419. http://dx.doi.org/10.1111/1467-9957.00309

Carkovic, M., \& R. Levine. (2005). Does FDI Accelerate Economic Growth? In Theodore Moran, Edward Graham and Magnus Blomstorn (eds.), Does Foreign Direct Investment Promote Development? Washington, DC: Institute of International Economics, pp. 195-220. 
Chakraborty, C., \& Basu, P. (2002). Foreign direct investment and growth in India: A cointegration approach. Applied Economics, 34, 1061-1073. http://dx.doi.org/10.1080/00036840110074079

Choe, J.I. (2003). Do Foreign Direct Investment and Gross Domestic promote Economic Growth? Review of Development Economics, 7(1), 44-57. http://dx.doi.org/10.1111/1467-9361.00174

Christopher, D. Carroll, D., \& Weil, N. (1994). Saving and growth: A reinterpretation, NBER Working Paper No. 4470, National Bureau of Economic Research, Cambridge.

Gavin, M., Hausmann, R., \& Talvi, E. (1997). Saving behavior in Latin America: overview and policy issues. Hausmann, R., Reisen, H. Promoting Saving in Latin America. Organization of Economic Cooperation and Development and Inter-America Development Bank, Paris.

Granger, C.W.J. (1969). Investigating causal relations by econometric models and cross-spectral methods. Econometrica, 37, 424-438. http://dx.doi.org/10.2307/1912791

Hermes, N., \& R. Lensink. (2003) Foreign Direct Investment, Financial Development and Economic Growth. The Journal of Development Studies, 40, 142-163. http://dx.doi.org/10.1080/00220380412331293707

Hsiao and Shen. (2003). Foreign Direct Investment and Economic Growth: The Importance of Institutions and Urbanization. Economic Development and Cultural Change, 51, 83-896.

Li, X., \& Liu, X. (2005). Foreign Direct Investment and Economic Growth: An Increasingly Endogenous Relationship. World Development, 33(3), 393-407. http://dx.doi.org/10.1016/j.worlddev.2004.11.001

Lutkepohl, H. (1982). Non-causality due to omitted variables. Journal of Econometrics, 19, 367-378. http://dx.doi.org/10.1016/0304-4076(82)90011-2

Marwah, K., \& Tavakoli, A. (2004). The Effects of Foreign Capital and Imports on Economic Growth. Journal of Asian Economics, 15, 399-413. http://dx.doi.org/10.1016/j.asieco.2004.02.008

Mohammad Salahuddin, Muhammad Shahbaz, \& Muhammad Irfan Chani. (2010). A Note on Causal Relationship between FDI and Savings in Bangladesh. Theoretical and Applied Economics, XVII(11), 53-62.

Narayan, P. K., \& Narayan, S. (2006). Savings behaviour in Fiji: an empirical assessment using the ARDL approach to cointegration. International Journal of Social Economics, 33(7), 468-480. http://dx.doi.org/10.1108/03068290610673243

Phillips, P. C. B., \& P. Perron. (1988). Testing for Unit Roots in Time Series Regression. Biometrika, 75, 335-345. http://dx.doi.org/10.1093/biomet/75.2.335

Sajid, G. M., \& M. Sarfraz. (2008). Savings and Economic Growth in Pakistan: An Issue of Causality. Pakistan Economic and Social Review, 46(1), 17-36.

Shahbaz M., Awan R., \& Ali L. (2008). Bi-Directional Causality between FDI \& Savings: A Case Study of Pakistan. International Research Journal of Finance and Economics, 17, pp. 75-83.

Sinha, D., \& T. Sinha. (1998). Cart Before the Horse? The Saving-Growth Nexus in Mexico. Economics Letters, 61, 43-47. http://dx.doi.org/10.1016/S0165-1765(98)00144-X

Sylwester, K. (2005). Foreign Direct Investment, Growth, and Income Inequality in Less Developing Countries. International Review of Applied Economics, 19(3), 289-300. http://dx.doi.org/10.1080/02692170500119748

Toda, H.Y., \& Yamamoto, T. (1995). Statistical inferences in vector autoregressions with possibly integrated processes. Journal of Econometrics, 66, 225-50. http://dx.doi.org/10.1016/0304-4076(94)01616-8

Uberto. Triacca. (1998). Non-causality: The role of the omitted variables. Economics Letters, 60, 317-320. http://dx.doi.org/10.1016/S0165-1765(98)00118-9

Waheed, A. (2004b). Aid-Savings Nexus: Co integration, Causality and Error Correction Modeling Approach. Journal of International Development Studies, 13(2), 15-29.

Zhang, K. H. (2001). How Does Foreign Investment Affect Economic Growth in China? Economics of Transition, 9, 679-693. http://dx.doi.org/10.1111/1468-0351.00095

Note

Note 1. Details to be reviewed in section 3 